\title{
A GESTÃO DEMOCRÁTICA NO PROGRAMA ESCOLA ATIVA/MEC - POLÍTICAS PARA O CONSENSO
}

\author{
Mara Regina Martins Jacomeli ${ }^{1}$ \\ Universidade Estadual de Campinas \\ Maria Angélica Cardoso ${ }^{2}$ \\ Universidade Federal de Mato Grosso do Sul
}

\section{RESUMO}

O artigo trata da análise da concepção de gestão democrática presente no Programa Escola Ativa, implementado pelo Ministério da Educação (MEC), o qual se destinava à melhoria da qualidade do ensino nas escolas multisseriadas. No Brasil, o Programa Escola Ativa teve início em 1997, sendo implantado em 1998 no Nordeste; em 1999 expandiu-se para o Norte e o Centro-Oeste; a partir de 2008, passou a atender às regiões Sul e Sudeste. Tinha como base a melhoria do ensino por meio da formação docente continuada e da gestão democrática. O Escola Ativa, em 2012, foi substituído pelo Programa Nacional de Educação do Campo, que manteve na proposta alguns princípios, como o da gestão democrática. A noção de gestão democrática tem relação direta com a implementação de instâncias de decisão entre os vários segmentos que compõem a escola. A concepção contida no documento da Escola Ativa atrela a gestão democrática à implementação dos Conselhos Escolares e dos Colegiados Estudantis. Após análise documental, questionamos o conceito de gestão e de democracia esposados pelos documentos oficiais. Em contrapartida, sugerimos uma prática social transformadora, quer nas escolas urbanas quer nas escolas do campo.

Palavras-chave: Escola Pública; Escola Multisseriada; Gestão Democrática. Política Educional.

\section{THE DEMOCRATIC MANAGEMENT IN PROGRAM "ESCOLA ATIVA/MEC" - POLICIES FOR CONSENSUS}

\begin{abstract}
The article is about the analysis of democratic management's conception which is present in program "Escola Ativa" implemented by the Ministry of Education (MEC), which was intended to improve the quality of teaching in multigrade schools. In Brazil, the program "Escola Atriva" began in 1997 and was implemented in 1998 in the Northeast; in 1999 expanded into the North and the Midwest; from 2008 on, began to serve the South and Southeast. It was based on the improvement of teaching through continuing teacher education and democratic management. The "Escola Ativa" in 2012, was replaced by the National Rural Education Program, which kept some of the proposed principles such as democratic management. The notion of democratic management is directly related to the implementation of decision sectors between the various segments that compose the school. The idea present in the programs's documents connect the democratic management to the implementation of School Boards and Students' associations. After analysis of documents, we question the concept of management and democracy espoused by official documents. In contrast, we suggest a transformative social practice, whether in urban schools and in schools field.
\end{abstract}

Key-words: Public School; Multigrade School, Democratic management; Educational Policy 


\section{RESUMEN}

El artículo trata el análisis diseño de la manejo democrática en el Programa Escuela Activa implementado por el Ministerio de Educación (MEC), que tenía por objeto la mejora de la calidad de la enseñanza en las escuelas multigrado. En Brasil, el Programa Escuela Activa se inició en 1997 y ejecutado en 1998 en el noreste; en 1999 ampliado en el Norte y en el Medio Oeste; a partir de 2008, comenzó a servir el sur y el sudeste. Fue sobre la base de la mejora de la enseñanza a través de la educación continua docente y la gestión democrática. La Escuela Activa en 2012, fue sustituido por el Programa Nacional de Educación Rural, que llevó a cabo el propuesto algunos principios tales como la gestión democrática. La noción de la gestión democrática está directamente relacionado con la ejecución de la toma de decisiones entre los distintos segmentos que conforman la escuela. El diseño que figura en el documento de Escuela Activa vincula la aplicación democrática de Consejos Escolares y universitarios Estudiantes gestión. Después de la revisión de escritorio, cuestionamos el concepto de la gestión y de la democracia defendida por los documentos oficiales. Por el contrario, se sugiere una práctica social transformadora, ya sea en las escuelas urbanas y en el campo de las escuelas.

Palabras clave: Escuela pública; Escuela Multisseriate; Gestión Democrática. Política Educativa.

\section{INTRODUÇÃO}

As escolas multisseriadas ${ }^{3}$, diferentemente das escolas seriadas (ou, ainda, unisseriadas), são organizadas em uma sala única, na qual se reúnem alunos pertencentes aos cinco anos da fase inicial do Ensino Fundamental, sob a regência de um único professor. além do termo escola multisseriada usa-se, também, turma ou classe multisseriada. No estado de São Paulo, por exemplo, usa-se, mais frequentemente, turmas multisseriadas, pois numa mesma escola pode haver tanto turmas multisseriadas quanto turmas seriadas.

Em seu nascedouro, as escolas multisseriadas atendiam tanto à população urbana periférica quanto à população rural, no entanto, atualmente se concentram quase que somente na zona rural; embora em pequeno número, ainda existem, na área urbana de algumas cidades interioranas.

Um alerta nos faz Saviani (1980, p. 197) sobre as escolas rurais que não foram criadas para atender aos interesses do homem do campo, mas "a escolarização do campo se revela um fenômeno decorrente da expansão das relações capitalistas no campo". Portanto, as escolas no campo tendem a se efetivarem conforme os padrões urbanos uma vez que a sociedade capitalista se organiza segundo os padrões urbano-industriais. Menezes e Santos (2002, p. 2), ao desenvolverem o verbete Escolas Multisseriadas, no Dicionário Interativo da Educação Brasileira ${ }^{4}$, não só definem classe multisseriada como afirmam que:

As classes multisseriadas existem principalmente nas escolas do meio rural, visando diminuir a evasão escolar, ou em projetos específicos, baseados na metodologia da aceleração e no telecurso, buscando atrair crianças e adolescentes em situação de rua, analfabetas ou defasadas em seus estudos, para que possam aprender e serem convencidos a continuar na vida escolar. 
Segundo Piza e $\operatorname{Sena}^{5}$ (2001, p. 13) as escolas multisseriadas são, historicamente, consideradas como de segunda categoria e, o que é pior, sem alternativa de melhoria; por isso, os legisladores optaram por esquecê-las, esperando que desapareçam como consequência natural do processo de desenvolvimento das sociedades. Porém, o desaparecimento natural não existe na história, trata-se, sempre, de funções sociais que as instituições cumprem ou deixam de cumprir para desaparecer ou para se recriar. Por essa razão, apesar de todas as mazelas e das políticas de substituição promulgadas desde a década de 1980, as escolas multisseriadas vêm resistindo e adentraram o século XXI, como pode ser visto no quadro a seguir:

Quadro 1 Número de Turmas Multisseriadas no Ensino Fundamental - 2000 a 2013.

\begin{tabular}{|c|c|c|c|c|c|c|c|c|c|c|c|c|c|c|}
\hline & 2000 & 2001 & 2002 & 2003 & 2004 & 2005 & 2006 & 2007 & 2008 & 2009 & 2010 & 2011 & 2012 & 2013 \\
\hline BR & 134.581 & 125.627 & 117.871 & 111.653 & 110.661 & 106.454 & 102.905 & 93.884 & 98.899 & 96.634 & 97.623 & 95.402 & 93.493 & 88.261 \\
\hline $\mathbf{N}$ & 23.271 & 23.041 & 21.977 & 21.495 & 21.005 & 20.811 & 19.984 & 19.229 & 20.480 & 20.594 & 21.762 & 21.833 & 21.581 & 21.237 \\
\hline RO & 2.666 & 2.492 & 2.216 & 2.012 & 1.703 & 1.637 & 1.227 & 712 & 730 & 686 & 544 & 532 & 483 & 407 \\
\hline $\mathrm{AC}$ & 1.363 & 1.431 & 1.392 & 1.452 & 1.459 & 1.540 & 1.523 & 1.409 & 1.602 & 1.545 & 1.613 & 1.659 & 1.634 & 1.613 \\
\hline $\mathrm{AM}$ & 4.182 & 4.339 & 4.301 & 4.367 & 4.410 & 4.535 & 4.749 & 5.136 & 5.333 & 5.602 & 5.752 & 5.914 & 5.883 & 5.841 \\
\hline RR & 554 & 587 & 561 & 519 & 560 & 511 & 457 & 420 & 386 & 392 & 463 & 442 & 484 & 505 \\
\hline $\mathrm{PA}$ & 12.022 & 11.843 & 11.375 & 11.231 & 10.983 & 10.803 & 10.324 & 10.026 & 10.835 & 10.821 & 11.812 & 11.709 & 11.562 & 11.479 \\
\hline $\mathrm{AP}$ & 388 & 410 & 431 & 379 & 389 & 434 & 419 & 283 & 346 & 435 & 534 & 527 & 545 & 511 \\
\hline TO & 2.096 & 1.939 & 1.701 & 1.535 & 1.501 & 1.351 & 1.285 & 1.243 & 1.248 & 1.113 & 1.044 & 1.050 & 990 & 881 \\
\hline $\mathbf{N E}$ & 75.027 & 70.812 & 66.645 & 62.803 & 62.135 & 59.818 & 58.261 & 55.618 & 57.474 & 56.389 & 56.858 & 55.212 & 53.537 & 49.518 \\
\hline MA & 12.353 & 11.592 & 11.089 & 11.014 & 10.727 & 10.858 & 10.953 & 11.023 & 11.586 & 11.731 & 12.533 & 12.825 & 12.663 & 12.122 \\
\hline $\mathrm{PI}$ & 6.706 & 6.291 & 5.966 & 5.777 & 5.485 & 5.347 & 5.184 & 4.547 & 4.647 & 4.369 & 4.332 & 4.261 & 4.315 & 3.689 \\
\hline $\mathrm{CE}$ & 8.352 & 7.450 & 6.609 & 6.382 & 7.350 & 7.108 & 6.623 & 6.723 & 6.745 & 5.857 & 5.033 & 4.333 & 4.217 & 3.876 \\
\hline $\mathrm{RN}$ & 2.372 & 2.398 & 2.317 & 2.159 & 2.146 & 1.892 & 2.108 & 1.837 & 1.926 & 1.876 & 1.948 & 1.914 & 1.871 & 1.807 \\
\hline $\mathrm{PB}$ & 5.904 & 5.385 & 5.083 & 4.867 & 4.761 & 4.567 & 4.637 & 5.008 & 5.045 & 5.137 & 5.178 & 4.952 & 4.600 & 4.148 \\
\hline $\mathrm{PE}$ & 8.864 & 8.598 & 7.889 & 7.620 & 7.721 & 7.583 & 7.288 & 6.757 & 7.360 & 7.190 & 7.072 & 6.870 & 6.703 & 6.084 \\
\hline $\mathrm{AL}$ & 2.484 & 2.427 & 2.249 & 2.177 & 2.098 & 2.046 & 2.064 & 2.029 & 2.285 & 2.296 & 2.334 & 2.246 & 2.192 & 1.992 \\
\hline SE & 1.423 & 1.357 & 1.275 & 1.356 & 1.409 & 1.245 & 1.212 & 1.145 & 1.218 & 1.265 & 1.443 & 1.487 & 1.551 & 1.607 \\
\hline $\mathrm{BA}$ & 26.569 & 25.314 & 23.868 & 21.451 & 20.438 & 19.172 & 18.192 & 16.549 & 16.662 & 16.668 & 16.985 & 16.324 & 15.425 & 14.193 \\
\hline SE & 18.872 & 17.550 & 16.908 & 16.076 & 16.779 & 16.003 & 15.016 & 11.962 & 13.188 & 12.019 & 11.488 & 10.983 & 11.069 & 10.346 \\
\hline MG & 11.884 & 10.732 & 10.192 & 9.463 & 10.584 & 10.013 & 9.705 & 8.285 & 8.245 & 7.912 & 7.412 & 7.194 & 7.193 & 6.167 \\
\hline ES & 2.514 & 2.406 & 2.270 & 2.173 & 2.131 & 2.165 & 1.968 & 1.892 & 1.799 & 1.763 & 1.615 & 1.568 & 1.420 & 1.402 \\
\hline RJ & 2.303 & 2.227 & 2.082 & 1988 & 1.957 & 1.793 & 1.599 & 1.530 & 1.399 & 1.357 & 1.169 & 1.053 & 1.019 & 1.319 \\
\hline SP & 2.171 & 2.185 & 2.364 & 2.452 & 2.107 & 2.032 & 1.744 & 255 & 1.745 & 987 & 1.292 & 1.168 & 1.437 & 1.458 \\
\hline SUL & 12.079 & 10.244 & 9.053 & 7.987 & 7.356 & 6.566 & 5.964 & 4.729 & 5.301 & 5.017 & 4.894 & 4.585 & 4.463 & 4.364 \\
\hline PR & 3.594 & 2.560 & 2.064 & 1.755 & 1.577 & 1.413 & 1.234 & 956 & 892 & 792 & 690 & 699 & 679 & 664 \\
\hline $\mathrm{SC}$ & 2.767 & 2.544 & 2.218 & 1.886 & 1.624 & 1.434 & 1.339 & 1.149 & 807 & 691 & 685 & 680 & 696 & 680 \\
\hline $\mathrm{RS}$ & 5.718 & 5.140 & 4.771 & 4.346 & 4.155 & 3.719 & 3.391 & 2.624 & 3.602 & 3.534 & 3.519 & 3.206 & 3.088 & 3.020 \\
\hline $\mathrm{CO}$ & 5.332 & 3.980 & 5.588 & 3.292 & 3.386 & 3.256 & 3.680 & 2.346 & 2.456 & 2.615 & 2.621 & 2.789 & 2.843 & 2.796 \\
\hline MS & 1.171 & 609 & 631 & 504 & 489 & 524 & 509 & 492 & 407 & 506 & 505 & 504 & 485 & 452 \\
\hline MT & 2.016 & 1.800 & 1.615 & 1.580 & 1.679 & 1.643 & 1.544 & 1.175 & 1.222 & 1.331 & 1.420 & 1.592 & 1.701 & 1.757 \\
\hline GO & 1.810 & 1.509 & 1.285 & 1.152 & 1.162 & 1.027 & 1.576 & 625 & 784 & 733 & 625 & 637 & 628 & 566 \\
\hline $\mathrm{DF}$ & 335 & 62 & 57 & 56 & 56 & 62 & 51 & 54 & 43 & 45 & 71 & 56 & 29 & 21 \\
\hline
\end{tabular}

Quadro organizado a partir dos dados colhidos nas Sinopses Estatísticas da Educação Básica de 2000 a 2013.

Disponíveis em WWW.inep.gov.br, link portal INEP/Informações Estatísticas/Sinopses Estatísticas.

Do quadro exposto depreendemos que, entre 2007 e 2010, ocorre um aumento no número de turmas multisseriadas de modo geral. Nas regiões Sul, Sudeste e Centro-Oeste os números também aumentam para, logo depois, voltar a cair, mas de forma menos acelerada do que vinha acontecendo antes de 2007. Essa oscilação provavelmente está ligada à expansão do Programa Escola Ativa, ocorrida neste ano. Por hora, trata-se de um campo aberto às novas pesquisas e que não será explorado nesse artigo.

Nas últimas décadas do século XIX e início do século XX, nas regiões urbanas, as escolas primárias ou de primeiras letras foram substituídas pelos grupos escolares e ali se organizou um novo modelo escolar, graduado e seriado que se estende aos dias atuais. Nas vilas e aldeias, porém, continuava a funcionar a escola isolada, anteriormente denominada 
escola preliminar, que, no decorrer do tempo, foi unida de forma quase idêntica à dos grupos escolares. Estas, então denominadas escolas reunidas, mantinham na mesma sala 60 a 100 alunos sob a direção de um só professor que realizava o ensino, empregando o método misto, uma mistura que podia ser tanto do ensino mútuo com o individual quanto do mútuo com o simultâneo.

Sobre as escolas primárias, ou de primeiras letras, sabe-se que, no período republicano, elas foram, gradativamente, substituídas por outro modelo de organização escolar: os grupos escolares que reuniam todas as características da escola graduada, conforme demonstra Souza (2006, p. 114):

[...] fundamentava-se essencialmente na classificação dos alunos pelo nível de conhecimento em agrupamentos supostamente homogêneos, implicando a constituição de classes. Pressupunha, também, a adoção do ensino simultâneo, a racionalização curricular, o controle e a distribuição ordenada dos conteúdos e do tempo [...], a introdução de um sistema de avaliação, a divisão do trabalho docente e um edifício escolar compreendendo várias salas de aula e vários professores.

Paralelamente se desenvolveram as escolas reunidas que, conforme Müller (2006, p. 17), constituíam um modelo muito similar aos grupos escolares, porém, ao agrupar as escolas isoladas mantinham as características destas. Contudo, nas regiões urbanas periféricas e na zona rural foram mantidas as escolas isoladas que, com o passar do tempo, passaram à denominação de escolas multisseriadas.

Embora consideradas de segunda categoria, as escolas multisseriadas vêm resistindo e fecharam o século XX totalizando 134.581 turmas em todo o território nacional e, mesmo tendo sofrido uma redução de aproximadamente $34,42 \%$, contam ainda com 88.261 turmas, conforme o censo escolar de $2013^{6}$.

Em suas pesquisas acerca das multisseriadas na Amazônia paraense, Hage (2007, p. 7) destaca a gravidade da situação em que se encontram essas escolas:

Apesar de concentrar mais da metade das escolas brasileiras, 97 mil de 169 mil existentes, a metade das escolas do campo ainda é de uma sala, 64\% são multisseriadas. Em relação aos professores, boa parte dos que ensinam no campo tem formação inadequada; e apenas $9 \%$ completaram o ensino superior.

Essa situação é reconhecida pelo Ministério da Educação e Cultura - MEC que, ao elaborar o documento Elementos para um Plano Nacional de Educação no Campo, escreve:

$\mathrm{Na}$ evolução do sistema de ensino brasileiro, tem sido determinante o fator de localização da população no que se refere à oferta de oportunidades de escolarização, podendo ser considerada muito alta a correlação positiva entre urbanização e oferta de ensino. Em contrapartida, em que pesem todas as transformações ocorridas na ampliação das oportunidades de ensino, sobretudo após os novos marcos legais instituídos pelas Constituintes e Lei de Diretrizes e Bases - Lei 9394/96, não houve alteração significativa na histórica defasagem do atendimento aos povos do campo em todos os níveis e modalidades com exceção, em certa medida, ao primeiro segmento do nível fundamental (BRASIL/MEC/SECAD - POR UMA POLÍTICA DE EDUCAÇÃO DO CAMPO).

A Lei de Diretrizes e Bases da Educação Nacional/LDBEN nº 9.394 de 1996, em seus 92 artigos distribuídos em nove títulos, discorre sobre a questão da educação para a população rural em apenas um artigo, dentro do quinto título composto por 17 artigos e onde trata Dos Níveis e das Modalidades de Educação e Ensino. É nesse artigo que as 
pesquisadoras Santos e Pinho (2002, p. 10) se basearam para analisar a questão do currículo na prática de professoras das escolas multisseriadas baianas. Reza o artigo que

Art. 28. Na oferta de educação básica para a população rural, os sistemas de ensino promoverão as adaptações necessárias à sua adequação às peculiaridades da vida rural e de cada região, especialmente:

I - conteúdos curriculares e metodologias apropriadas às reais necessidades e interesses dos alunos da zona rural;

II - organização escolar própria, incluindo adequação do calendário escolar às fases do ciclo agrícola e às condições climáticas;

III - adequação à natureza do trabalho na zona rural. (LDBEN nº 9.394 de 1996).

As autoras (2002, p. 10) advertem para o vazio existente na legislação: "vale dizer que desconhecemos alguma política local que regulamente o sistema de ensino, levando em consideração as peculiaridades do rural e, com isso, a especificidade do currículo e sua prática".

O Plano Nacional de Educação - PNE/2001-2010 - sinalizava um tratamento diferenciado para as escolas rurais propondo a substituição das classes multisseriadas pela ampliação da oferta de quatro séries regulares, pelo sistema de nucleação, para as séries iniciais. Nas escolas em que se ministravam as séries finais do Ensino Fundamental a proposta foi a instalação da Pedagogia da Alternância. Na nucleação as:

[...] classes multisseriadas são extintas e seus alunos transferidos para escolas pólos onde, então, podem ser agrupados por séries ou ciclos. Algumas questões são importantes para que essa nucleação ocorra de forma satisfatória, como: o transporte escolar, o tempo que os alunos levam até a escola, a não desvalorização do saber rural e a contextualização (BRASIL, TV ESCOLA, 2001. PROGRAMA SALTO PARA O FUTURO, PGM 4).

Já a Pedagogia da Alternância é uma:

[...] proposta de trabalho pedagógico na qual os alunos $\left(5^{\mathrm{a}}\right.$ à $8^{\mathrm{a}}$ série $\mathrm{e}$ Ensino Médio) podem permanecer na escola durante uma semana e alternam uma semana em casa - isso ajuda as famílias que precisam dos filhos para o trabalho no campo. Dessa forma, existe a valorização do trabalho rural (BRASIL, TV ESCOLA, 2001. PROGRAMA SALTO PARA O FUTURO, PGM 4).

No entanto, para as regiões consideradas menos desenvolvidas as alternativas são outras. Em 1998, o MEC/Projeto Nordeste iniciou o processo de implantação da Proposta Escola Ativa. No ano seguinte, com o Programa FUNDESCOLA essa proposta foi expandida às regiões Norte e Centro-Oeste. A partir de 2008 passou a atender às cinco regiões brasileiras. A Escola Ativa é

[...] uma proposta metodológica voltada para classes multisseriadas que combina, na sala de aula, uma série de elementos e de instrumentos de caráter pedagógico/administrativo, cuja implementação objetiva aumentar a qualidade do ensino oferecido naquelas classes [as multisseriadas] (BRASIL, TV ESCOLA, 2001. PROGRAMA SALTO PARA O FUTURO, PGM 3).

Hage (2006, p. 4), baseando-se no documento Elementos para um Plano Nacional 
de Educação no Campo aponta que " $64 \%$ das escolas que oferecem ensino fundamental de $1^{\mathrm{a}}$ a $4^{\mathrm{a}}$ série são formadas por classes multisseriadas e apresentam muitos desafios para garantir às populações do campo seu direito à escolarização obrigatória". Afirma ainda que, "as escolas multisseriadas, em que pesem todas as mazelas explicitadas, têm assumido a responsabilidade quanto à iniciação escolar da grande maioria dos sujeitos no campo". Conforme dados do censo escolar, em 2012, eram 1.140799 brasileiros atendidos nos anos iniciais do Ensino Fundamental, em escolas multisseriadas. Daí a necessidade de buscas por alternativas que garantam a melhor qualidade para a educação no meio rural e, consequentemente, para as escolas multisseriadas.

Já a alternativa proposta pelos Parâmetros Curriculares Nacionais (BRASIL, 1997, p. 99) orienta para que, nas escolas multisseriadas, o ensino ocorra pela reunião dos alunos em grupos "que não sejam estruturados por série e sim por objetivos, em que a diferenciação se dê pela exigência adequada ao desempenho de cada um".

O novo Plano Nacional de Educação - PNE 2014-2024 - aprovado pela Lei 13.005 de 25 de junho de 2014, estabelece no artigo $8^{\circ}, \S 1^{\circ}$, inciso II que os Estados, o Distrito Federal e os Municípios deverão elaborar seus correspondentes planos de educação estabelecendo "considerem as necessidades específicas das populações do campo e das comunidades indígenas e quilombolas, asseguradas a equidade educacional e a diversidade cultural." Para tanto, doze, dentre as vinte metas deste PNE, tem estratégias voltadas para a educação das populações camponesas. Por exemplo, a Meta 1 refere-se à universalização da Educação Infantil na pré-escola para as crianças de quatro a cinco anos de idade. Dentre as dezessete estratégias traçadas para se alcançar esta meta, a décima reza: "fomentar o atendimento das populações do campo e das comunidades indígenas e quilombolas na Educação Infantil nas respectivas comunidades, por meio do redimensionamento da distribuição territorial da oferta, limitando a nucleação de escolas e o deslocamento de crianças, de forma a atender às especificidades dessas comunidades, garantido consulta prévia e informada". Desta mesma forma, as outras metas trazem, em suas estratégias, uma voltada para as populações camponesas. Em nenhum momento a questão das turmas multisseriadas é posta neste novo PNE.

Mas, buscando entender o momento histórico em que surge o Programa Escola Ativa, voltemos ao projeto de 1998, o MEC/Projeto Nordeste, que implantou a proposta que vigorou, no Brasil, até 2012.

\section{O PROGRAMA ESCOLA ATIVA E A CONCEPÇÃO DE GESTÃo DEMOCRÁTICA}

Buscando contextualizar a organização escolar brasileira, tem-se que:

A partir dos anos 90, o Banco Mundial (BIRD) vem adquirindo expressiva importância no âmbito das políticas públicas brasileiras. Esta evolução pode ser explicada pelo papel que o Banco desempenha junto aos países mais pobres, como estrategista do modelo neoliberal de desenvolvimento e também como articulador da interação econômica entre as nações, inclusive, para a negociação de sua dívida externa (FONSECA, 2001, p. 46).

Vale lembrar que a partir da Conferência Mundial de Educação para Todos, realizada na Tailândia em 1990, o Banco Mundial assumiu maior importância política junto ao setor educacional. Em 1993, ocorreu a Conferência de Nova Delhi, congregando os nove países mais populosos do mundo: Brasil, México, China, Índia, Paquistão, 
Bangladesh, Egito, Nigéria e Indonésia. As recomendações dessas conferências internacionais foram incorporadas no Plano Decenal Brasileiro para a Educação. E é nesse contexto de determinações políticas de organismos internacionais que, na segunda metade dos anos de 1990, é implantado o Programa Escola Ativa.

Do ponto de vista teórico e metodológico, o Programa Escola Ativa fundamentouse nos princípios da Escola Nova que chegou ao Brasil na década de 1920. Na década de 1970, "o escolanovismo orientou a proposta formulada na Colômbia do Programa Escuela Nueva, criado para atender às classes multisseriadas" (BRASIL, MEC/SECAD, 2010. Projeto Base/Escola Ativa, p. 13). O projeto colombiano chegou ao Brasil via Banco Mundial:

[...] em maio de 1996, um grupo de técnicos da Direção-Geral do Projeto Nordeste (Projeto Educação Básica para o Nordeste), projeto do Ministério da Educação, e técnicos dos estados de Minas Gerais e Maranhão foram convidados pelo Banco Mundial a participarem, na Colômbia, de um curso sobre a estratégia "Escuela Nueva - Escuela Ativa", desenhada por um grupo de educadores colombianos que, há mais de 20 anos, atuavam com classes multisseriadas daquele país (BRASIL, MEC/SECAD, 2010. Projeto Base/Escola Ativa, p. 14).

Sua implantação, no Brasil, ocorreu em 1997, tendo por objetivo "aumentar o nível de aprendizagem dos educandos, reduzir a repetência e a evasão e elevar as taxas de conclusão das séries iniciais do Ensino Fundamental nas escolas multisseriadas do campo" (BRASIL, MEC/SECAD, 2010. Projeto Base/Escola Ativa, p. 14). Queiroz e Mendes Sobrinho (2004, p. 5) resumem a primeira proposta apresentada pelo MEC (1997-2007) da seguinte forma:

O modelo apresentado pelo Projeto para trabalhar com classes multisseriadas, segundo a proposta apresentada pelo MEC (1999), propõe a promoção da aprendizagem baseada na compreensão, respeitando o ritmo de aprendizagem do aluno, o papel do professor como orientador e avaliador, a participação e a aprendizagem cooperativa, incorporando assim, recursos didáticos à aula, como livros didáticos, biblioteca-aula, cantinho de trabalho, bem como procura promover estratégias vivenciais como governo estudantil e os comitês, visando a aprendizagem da democracia, da participação, da vida cívica e da convivência e a estimular hábitos de colaboração, companheirismo, solidariedade, participação e tolerância. A promoção do aluno é progressiva e flexível, respeitando o ritmo de aprendizagem de cada um. O conceito de repetência é eliminado.

Em 2007, o Programa Escola Ativa foi transferido do FNDE/FUNDESCOLA para a Secretaria de Educação Continuada, Alfabetização e Diversidade - SECAD, ficando sua gestão a cargo da Coordenação Geral de Educação do Campo. Conforme consta no Projeto Base (BRASIL, MEC/SECAD, 2010. Projeto Base/Escola Ativa, p. 17) "o atual momento desafia o Programa a reconhecer a realidade do campo enquanto fonte de suas reflexões, e superar uma visão reducionista do campo". Dentro desta compreensão "a Educação do Campo é entendida como forma de ação político-social, em oposição à tradicional educação rural, transposição empobrecida da educação construída para as áreas urbanas" (IDEM, p. 18). Nesse contexto, "a escola passa a ser reconhecida como espaço de reflexão da realidade dos povos do campo, de seu trabalho, suas linguagens, de suas 
formas de vida e, sobretudo, de um novo projeto político de desenvolvimento" (IDEM, p. $18)$.

Nessa reformulação do Programa Escola Ativa considera-se como desafio fundamental das escolas do campo implementar uma educação que recupere as condições humanas dos povos do campo. Para tanto, advoga princípios que sustentam tais propósitos e estabelece coerência com essa concepção de educação, quais sejam:

Educação para transformação social - vínculo orgânico entre processos educativos, políticos, econômicos e culturais; educação para o trabalho e a cooperação; educação voltada para as várias dimensões da pessoa humana; educação voltada para valores humanistas; e educação como processo permanente de formação e transformação humana (BRASIL, MEC/SECAD, 2010. Projeto Base/Escola Ativa, p. 20).

Esses princípios se desdobram no trabalho pedagógico e orientam a relação com o conhecimento, propondo que a aprendizagem ocorra por meio da ação humana e mediante a apropriação criativa, bem como com a reelaboração de conceitos. Nesse sentido, os conteúdos escolares são pensados para estabelecerem a relação especificidade/universalidade e abordarem temas que tratam de grandes problemas que afetam a vida cotidiana.

Nas palavras de Rosa e Bezerra (2014, p. 81-82) a estratégia do Programa Escola Ativa apresenta dois componentes, um de trabalho pedagógico e outro de gestão escolar, que interconectados compõem a metodologia do programa. O primeiro é composto de "cadernos de autoaprendizagem" e de uma organização da sala de aula em cantinhos temáticos. Em outro artigo, Rosa e Bezerra (2013, p. 34-35) revelam que esse componente pedagógico

[...] tem tendências construtivistas. O construtivismo, de acordo com Silva (1996, p. 216- 219), acentuou uma tendência de psicologização na escolarização das massas que acarretou a despolitização da educação, na medida em que a escola de massas procurou esconder seu vínculo com a política ao adotar um tratamento psicológico da aprendizagem e do ensino e ao priorizar a aprendizagem individual, sem conexão com a sociedade e com o contexto institucional.

Para o outro componente, a gestão escolar, propõe-se que haja um "envolvimento entre escola e comunidade, contextualizado em seus processos sociais e organizativos por meio do Conselho Escolar" (BRASIL, MEC/SECAD, 2010. Projeto Base/Escola Ativa, p. 21). Cabe a este Conselho congregar os segmentos escolares - gestores, professores e funcionários - e a comunidade local "para, juntos, construírem uma educação de qualidade e socialmente relevante" (MEC/SECAD, 2006, p. 50).

De acordo ainda com o Projeto Base da Escola Ativa (IDEM, p. 22 e 23), a gestão da escola deve ser democrática, ou seja:

[...] corresponde à participação da comunidade na elaboração do projeto pedagógico da escola, na definição de prioridades e na organização de tarefas administrativas e do Projeto Base, gestão dos recursos da própria unidade escolar, bem como ao cuidado com o patrimônio da escola. Para o Programa Escola Ativa, a gestão democrática encontra-se concretizada no elemento curricular 'Colegiado Estudantil' e nos outros instrumentos de participação que chamam os estudantes para assumir 
responsabilidades ante a escola e a comunidade, valorizando a experiência extra-escolar, as formas de trabalho e sobrevivência e relação com o meio ambiente que respondem, juntos, pela grande diversidade das populações do campo.

Ao Colegiado Estudantil cabe fortalecer a participação dos estudantes e da comunidade, estimulando "a auto-organização dos estudantes, a tomada de decisões coletivas, a cogestão" (BRASIL, MEC/SECAD, 2010. Projeto Base/Escola Ativa, p. 34).

Poderíamos considerar estes elementos como uma estratégia governamental de desoneração quanto à educação popular?

Da mesma maneira, a noção de gestão democrática apresentada no documento de Orientações Pedagógicas para a formação de educadores e educadoras, da Escola Ativa, tem relação direta com a implementação de instâncias de decisão entre os vários segmentos que compõem a escola: gestores, funcionários, professores, alunos e pais. Dessa maneira, sem problematizar qual a concepção de gestão democrática que está sendo implementada, o documento citado identifica a gestão democrática atrelando-a a implementação dos Conselhos Escolares e dos Colegiados Estudantis. Assim, a gestão democrática se faz a partir da participação dos vários segmentos escolares que organizados e participativos colaborariam com a aprendizagem dos alunos.

\section{PROBLEMATIZANDO A GESTÃO ESCOLAR}

É necessário problematizarmos um pouco de que gestão escolar estava se falando. Oliveira (2001, p. 91) ao analisar a escola como núcleo da gestão afirma que:

$\mathrm{Na}$ gestão da educação pública, os modelos fundamentados na flexibilidade administrativa podem ser percebidos na desregulamentação de serviços e na descentralização dos recursos, posicionando a escola como núcleo do sistema. São modelos alicerçados na busca de melhoria da qualidade de educação, entendida como um objetivo mensurável e quantificável em termos estatísticos, que poderá ser alcançado a partir de inovações incrementais na organização e gestão do trabalho na escola.

A política de descentralização materializou-se nas décadas de 1970 e 1980. Conforme Rosar (2001, p. 106) a política educacional para o primeiro grau, após a Lei 5.692/71 objetivou, no âmbito de projetos federais, "induzir a municipalização do ensino, transferindo encargos para o município, sem que se efetivasse um investimento financeiro satisfatório nessa instância". Dentre esses projetos, continua a autora, destacaram-se o Promunicípio, o Edurural, o Polonordeste, o Pronasec e o Projeto Nordeste. Todos financiados pelo Banco Mundial e trazendo uma concepção e diretrizes educacionais definidas a priori por essa instituição. Vale lembrar que o Programa Escola Ativa foi implantado pelo Projeto Nordeste, após os técnicos do Programa terem participado do curso na Colômbia, a convite do Banco Mundial.

Luce e Medeiros (2008), analisando o Programa Salto para o Futuro, veiculado em 2005 pela TV Escola, afirmam que a gestão democrática da educação deveria organizar ações: 
[...] que desencadeiem a participação social na formulação de políticas educacionais; no planejamento; na tomada de decisões; na definição do uso de recursos e necessidades de investimento; na execução das deliberações coletivas; nos momentos de avaliação da escola e da política educacional. Também a democratização do acesso e estratégias que garantam a permanência na escola, tendo como horizonte a universalização do ensino para toda a população, bem como o debate sobre a qualidade social dessa educação universalizada [...]. Esses processos devem garantir e mobilizar a presença dos diferentes atores envolvidos, que participam no nível dos sistemas de ensino e no nível da escola.

Conforme as autoras, em nível prático, encontramos diferentes vivências dessa proposta, como a introdução de modelos de administração empresariais, ou processos que respeitam a especificidade da educação enquanto política social, buscando a transformação da sociedade e da escola, através da participação e construção da autonomia e da cidadania. Falar em gestão democrática nos remete, portanto, quase que imediatamente a pensar em autonomia e participação. $\mathrm{O}$ que podemos dizer sobre esses dois conceitos, já que há diferentes possibilidades de compreendê-los? (LUCE; MEDEIROS, 2008).

Quanto à autonomia, as autoras alertam que o conceito deve ser muito bem trabalhado, "a fim de equacionar a possibilidade de direcionamento camuflado das decisões, ou a desarticulação total entre as diferentes esferas, ou o domínio de um determinado grupo, ou, ainda, a desconsideração das questões mais amplas que envolvem a escola" (Idem). Quanto à participação - que também pode ter muitos significados, além de poder ser exercida em diferentes níveis - ela pode ser pensada em todos os momentos do planejamento da escola, de execução e de avaliação ou pensar que participação pode ser apenas convidar a comunidade para eventos ou para contribuir na manutenção e conservação do espaço físico. Essas questões devem estar presentes nas discussões da gestão na escola e nos espaços de definição da política educacional de um município, do estado ou do país.

As autoras questionam ainda os instrumentos e práticas que organizam a vivência da gestão escolar. Segundo elas,

[...] em geral, esses processos mesclam democracia representativa instrumentos e instâncias formais que pressupõem a eleição de representantes, com democracia participativa - estabelecimento de estratégias e fóruns de participação direta, articulados e dando fundamento a essas representações (LUCE; MEDEIROS, 2008).

Ao problematizar a questão da democracia Luce e Medeiros (2008) afirmam que deve haver uma mescla entre democracia representativa e democracia participativa. No entanto, um dos objetivos e prioridades da gestão democrática da escola, no primeiro Programa Salto para o Futuro reza que:

O PNE, seguindo o princípio constitucional e a diretriz da LDB, define entre seus objetivos e prioridades:

[...] a democratização da gestão do ensino público, nos estabelecimentos oficiais, obedecendo aos princípios da participação dos profissionais da educação na elaboração do projeto pedagógico da escola e a participação das comunidades escolar e local em conselhos escolares ou equivalentes" (BRASIL, TV ESCOLA, 2005. PROGRAMA SALTO PARA O FUTURO/GESTÃO DEMOCRÁTICA DA ESCOLA/PROGRAMA 1). 
No terceiro Programa, o consultor Genuíno Bordignon afirma que:

Na gestão democrática da escola cidadã, além da autonomia, da participação e das formas de escolha de conselheiros e dirigentes, a prática do cotidiano da sala de aula e dos gabinetes burocráticos precisa estar ancorada em princípios coerentes com as finalidades da educação emancipadora. Princípios que orientem efetivamente a prática dos educadores (BRASIL, TV ESCOLA, 2005. PROGRAMA SALTO PARA O FUTURO/GESTÃO DEMOCRÁTICA DA ESCOLA/PROGRAMA 3).

Como já dissemos, as autoras estão analisando o Programa Salto para o Futuro veiculado pela TVE, em 2005, portanto referente à primeira fase do Programa Escola Ativa.

Embora os documentos expressem, em todo seu conteúdo, que o modelo de gestão é o democrático, Rosa e Bezerra (2014, p. 80) afirmam que a concepção adotada no Programa Escola Ativa é o "da gestão gerencial e está intrinsecamente ligado à descentralização empreendida pelas reformas neoliberais da administração pública na América Latina."

Para Ribeiro (2011, p. 35):

Na política adotada pelo MEC, orientada pela concepção de escola ativa, é
na gestão que se mostra, com maior clareza, o que entendemos como
reação à educação do campo. Embora já referida anteriormente, nas
críticas de Oliveira, Fonseca, Toschi (2005), a concepção de gestão escolar
proposta nessa política contrapõe-se à dimensão democrática implícita na
Lei de Diretrizes e Bases da Educação Nacional (LDB) 9.394/96. Ao
contrário, a política adotada pelo MEC baseia-se no conceito de gestão
racional, referenciada em ferramentas de gestão, atributos gerenciais e
treinamento de pessoal, uma tendência denunciada por Saviani (2007)
como indício da retomada do tecnicismo dos anos de 1970, porém sob uma
nova roupagem.

No início das discussões acerca da gestão escolar democrática, por volta de meados da década de 1980, Paro (1987, p. 52) problematizava a questão. Falando do ponto de vista dos trabalhadores, o autor assumia como "premissa o fato de que, da classe dominante, não se pode esperar nenhuma iniciativa de transformação em favor das camadas dominadas, (e, no nosso caso, no que se refere à escola), sem pressão por parte dos interessados." É nesse sentido que ele questionava a participação da comunidade escolar na "gestão democrática". Primeiro, porque a escola que estava posta não cumpria sua função de "levar as classes trabalhadoras a se apropriarem de um saber historicamente acumulado e desenvolver a consciência crítica". Segundo, porque o que tínhamos era um sistema hierárquico que pretensamente colocava todo o poder nas mãos do diretor. Contudo era um poder limitado por questões financeiras e critérios problemáticos de avaliação, gerando, na verdade, uma impotência e falta de autonomia do diretor que sintetizava esses fatores na própria escola. "E se escola não tem sequer autonomia, se a escola é impotente, é a própria classe trabalhadora que fica privada de uma das instâncias através das quais ela poderia apropriar-se do saber e da consciência crítica" (PARO, 1987, p. 52). Conforme Paro (1987, p. 52) é preciso que a classe trabalhadora busque a reorganização da autoridade no interior da escola. A terceira questão seria conseguir a participação de todos os setores da escola - educadores, alunos, funcionários e pais - nas decisões a respeito dos objetivos e funcionamento da escola. Paro (1987, p. 53) viu no Conselho de Escola uma potencialidade a ser explorada. Para ele, o Conselho "é um instrumento que existe e que precisa ser aperfeiçoado com vistas a que ele se torne o embrião de uma verdadeira gestão colegiada que esteja articulada com os interesses 
populares na escola". Para tanto é preciso que a escola primeiro, instrumentalize, pela conscientização e pela transmissão dos conhecimentos historicamente acumulados, os sujeitos que participam nesse processo.

Embora aponte vários problemas que obstaculizam a implantação efetiva da gestão escolar democrática, Paro (1987, p. 53) acredita que ela seja possível contanto que a classe trabalhadora não cruze os braços e espere "passivamente que a classe dominante, através de suas reformas e acomodações de interesses continue fazendo-nos engolir a soluções paliativas que a mantém perenemente no poder".

Claro que o debate que Paro estabelece situa-se num momento histórico em que os movimentos sociais, incluindo aí os dos educadores, estão a clamar por uma sociedade democrática e participativa, que rompesse com o passado da ditadura militar. Então as bandeiras da participação e da gestão democrática eram bandeiras que garantiriam uma atuação da comunidade escolar, sem os desmandos verificados com a repressão advinda da ditadura. As conquistas sociais sobre essa questão, portanto, refletiu na incorporação da gestão democrática na letra da lei, como foi o caso da incorporação na Constituição Federal de 1988. E se ela não foi implementada como se queria nos idos da década de 1980, já é outra história. Vide o caso do modelo de gestão empresarial que passa a ser defendido pelo Estado brasileiro, na década de 1990, e incorporado na própria formulação da LDBEN de 1996. O modelo de gestão então adotado estaria de acordo com a implementação do neoliberalismo e com a lógica de mercado. Assim, a escola passaria a ser administrada como uma empresa, com a lógica produtivista. Dessa forma, todo o debate político da década de 1980 é substituído por políticas educacionais que "despolitizaram" o interior da escola.

Cury (2001), analisando a gestão escolar no âmbito do Conselho Nacional de Educação, faz algumas considerações, dentre as quais destacamos:

De todo modo, talvez seja importante reter que o princípio da gestão
democrática tem um interlocutor (oculto?) que é o autoritarismo
hierárquico de que se revestiu tanto a administração das redes quanto a
própria relação pedagógica. E ela possui uma intencionalidade clara: ou a
gestio rei publicae [gestão da coisa pública] inclui a participação dos
envolvidos na educação escolar ou ela não é pública e aí o que se segue é a
gestio negotiorum [gestão de negócios] (CURY, 2001, p. 202).

Apesar dos problemas apontados, Cury (2001, p. 206) afirma que se trata de um avanço e que "o desafio posto aos sujeitos interessados na educação escolar e sua qualidade será o de encontrar, no interior destes avanços, o caminho consequente e viável de sua efetivação".

Paro (1987) além de problematizar a participação, traz à tona as questões da função educativa que a escola não cumpria e da hierarquização do sistema de ensino. Cury (2001) corrobora tanto no aspecto da participação quanto no da hierarquia. Contudo, ambos vêm na gestão avanços que precisam ser devidamente apropriados pelos sujeitos interessados na educação escolar.

No finalzinho do século XX uma das grandes conquistas no campo da educação foi a quase universalização do Ensino Fundamental. Entretanto, Frigotto (2007) afirma que essa quase universalização do Ensino Fundamental se efetivou dentro de uma profunda desigualdade intra e entre regiões e na relação cidade/campo. A diferenciação e a dualidade dão-se pelo não acesso efetivo e democrático ao conhecimento. A escola pública dos pobres e/ou dos filhos dos trabalhadores é uma escola que "cresce para menos", ou seja, 
cresce quantitativamente e decresce qualitativamente. Frente a essa colocação perguntamos: o que podemos fazer para reverter esse "crescimento"?

Para Saviani (1980, p. 51) a função das instituições educacionais seria de "ordenar e sistematizar as relações homem-meio para criar as condições ótimas de desenvolvimento das novas gerações [...]. Portanto, o sentido da educação, a sua finalidade, é o próprio homem, quer dizer, a sua promoção". Conforme Saviani (1980, p. 52) promover o homem significa "torná-lo cada vez mais capaz de conhecer os elementos de sua situação a fim de poder intervir nela transformando-a no sentido da ampliação da liberdade, comunicação e colaboração entre os homens". Isso implica definir para a educação sistematizada objetivos claros e precisos, quais sejam: educar para a sobrevivência, para a liberdade, para a comunicação e para a transformação. Nesse sentido, Saviani (1980, p. 172) defende a luta pela difusão de oportunidades e pela extensão da escolaridade do ponto de vista qualitativo. Para tanto, as escolas deveriam assumir a função que lhes cabe, qual seja: a de dotar a população dos instrumentos básicos de participação na sociedade.

Considerando que a escola é determinada socialmente, que a sociedade está fundada na produção capitalista, dividida em classes com interesses antagônicos e que, portanto, a escola sofre a determinação do conflito de interesses que caracteriza a sociedade, Saviani afirma que a escola é marcada pela tendência à conservação. Mas a superação dessa função conservadora é possível pela retomada vigorosa da luta contra a seletividade, a discriminação e o rebaixamento do ensino para as camadas populares garantindo aos trabalhadores o acesso ao conhecimento historicamente acumulado pelos homens.

Cardoso e Lara (2009, p.1.325) ao analisarem as funções sociais da escola pública à luz de cinco historiadores - Pierre Bourdieu (1999), Pérez Gómez (1998), Dermeval Saviani (1980, 1983), Antônio Gramsci (1979, 1989) e Gilberto Luiz Alves (2001) concluem que são "cinco pontos de vista diferentes e uma convergência: o caminho que a escola deve seguir para superar o status quo, qual seja, resgatar o conhecimento historicamente acumulado e possibilitar o acesso dos trabalhadores a esse conhecimento".

É esse trabalhador conhecedor de sua situação - seja da cidade, seja do campo que o sistema teme. Conforme Demo (2006, p. 17):

Sistemas inteligentes não reprimem simplesmente possíveis rebeldes; preferem aliciá-los com artimanhas pretensamente inclusivas, mas que incluem na margem; o pobre continua marginalizado, mas sente-se incluído porque recebe alguns benefícios residuais. De fato, o sistema não teme um pobre com fome; teme um pobre que sabe pensar. O lado mais interessante da politicidade é este: a gestação de sujeitos críticos e criativos, capaz de construir cidadanias organizadas e influentes, de elaborar contra-ideologias efetivas, de oferecer alternativas com base na arte de bem pensar para argumentar.

Formar esse trabalhador implica garantir-lhe acesso aos conhecimentos historicamente produzidos pelos homens, levando-o a conhecer sua situação sendo capaz de nela intervir.

Como fazer então essa formação em tempos que a escola passa por profunda crise de identificação? Primeiramente precisamos problematizar essa escola que aqui temos. Segundo Sanfelice (2005, p.102) a educação pública é algo a ser construído no âmbito das relações contraditórias que impulsionam as sociedades e, portanto os homens. A escola do povo - quer no campo ou na cidade, quer seriada ou quer multisseriada - deve ser o objetivo a ser alcançado, no âmbito de uma perspectiva revolucionária. Para tanto, afirma 
Mészáros, (2005), também no âmbito educacional as soluções não podem ser formais; elas devem ser essenciais. Em outras palavras, elas devem abarcar a totalidade das práticas educacionais da sociedade estabelecida.

No entanto, o oferecimento de uma educação básica de boa qualidade, em termos universalizantes, se contraporia à uma das principais funções da educação formal nas nossas sociedades que "é produzir tanta conformidade ou consenso quanto for capaz (MÉSZÁROS, 2005, p. 45). Nesse sentido, o autor adverte que esperar da sociedade mercantilizada uma sanção ativa de um mandato que estimule as instituições de educação formal a abraçar plenamente a grande tarefa histórica do nosso tempo, ou seja, a tarefa de romper com a lógica do capital no interesse da sobrevivência humana, seria um milagre monumental. Nesse contexto a baixa qualidade do ensino nas escolas públicas, seja seriada ou multisseriada, permanece. E aí, a pergunta se repete: o que e como fazer?

Segundo, há que se lutar por políticas públicas que garantam o acesso à educação, bem como o Estado assuma materialmente a oferta de educação, em todos os níveis, para todos. Mas não qualquer educação. Há que ser uma educação pensada prática e teoricamente, conforme propõe Saviani (2005, p. 107):

A prática será tanto mais coerente e consistente, será tanto mais qualitativa, será tanto mais desenvolvida quanto mais consistente e desenvolvida for a teoria que a embasa, e que uma prática será transformada à medida que exista uma elaboração teórica que justifique a necessidade da sua transformação e que proponha as formas da transformação, estamos pensando a prática a partir da teoria. Mas é preciso também fazer um movimento inverso, ou seja, pensar a teoria a partir da prática.

Voltamos à questão de resgatar o conhecimento historicamente produzido e possibilitar o acesso dos trabalhadores a esse conhecimento. E qual o papel da gestão escolar nesse cenário? De acordo com Mészáros (2005, p. 74) para romper o círculo vicioso de desperdício e de escassez é preciso "uma intervenção efetiva na educação, capaz, simultaneamente, de estabelecer prioridades e de definir as reais necessidades, mediante plena e livre deliberação dos indivíduos envolvidos." Mas não é esta a proposta da gestão escolar democrática e participativa?

Já falamos muito da gestão e que seu qualificativo é ser democrática. Ora, como pensar o democrático numa sociedade cindida em classes sociais antagônicas, onde o Estado também é uma instituição de classe? Segundo $\mathrm{Wood}^{7}$, o capitalismo é um modo de produção social incompatível com a democracia, isso,

[...] se por "democracia" entendemos tal como o indica sua significação literal, o poder popular ou o governo do povo. Não existe um capitalismo governado pelo poder popular no qual o desejo das pessoas seja privilegiado aos dos imperativos do ganho e da acumulação e, no qual, os requisitos da maximização do benefício não ditem as condições mais básicas de vida. $\mathrm{O}$ capitalismo é estruturalmente antitético em relação à democracia, em princípio, pela razão histórica mais óbvia: não existiu nunca uma sociedade capitalista na qual não tenha sido atribuído à riqueza um acesso privilegiado ao poder. Capitalismo e democracia são incompatíveis também, e principalmente, porque a existência do capitalismo depende da sujeição aos ditames da acumulação capitalista e às "leis" do mercado das condições de vida mais básicas e dos requisitos de reprodução social mais elementares, e esta é uma condição irredutível. 
Isso significa que o capitalismo necessariamente situa cada vez mais esferas da vida cotidiana fora do parâmetro no qual a democracia deve prestar conta de seus atos e assumir responsabilidades. Toda prática humana que possa ser convertida em mercadoria deixa de ser acessível ao poder democrático. Isso quer dizer que a democratização deve ir da mão da "desmercantilização". Mas desmercantilização por definição significa o final do capitalismo.

Segundo a mesma autora, o modelo dominante de democracia esposado pelo capitalismo acaba substituindo a ação política pela cidadania passiva, na medida em que enfatiza os direitos passivos em lugar dos direitos ativos, evitando, assim, "qualquer confrontação com concentrações de poder social, particularmente se for com as classes dominantes, e finalmente, despolitizando a política" (IDEM, p. 4).

Wood (IDEM, p. 7 e 8) também nos alerta que esse modelo de democracia, que ela chama de formal, implica no fato de que:

A esfera política concebida como o espaço onde as pessoas se comportam em seu caráter de cidadão - antes que como trabalhadores ou capitalistas - está separada do âmbito econômico. As pessoas podem exercitar seus direitos como cidadãos sem afetar muito o poder do capital no âmbito econômico. Ainda em sociedades capitalistas com uma forte tradição intervencionista do Estado, os poderes de exploração do capital costumam ficar intactos pela ampliação dos direitos políticos. Destarte, é óbvio que a democracia nas sociedades capitalistas significa algo muito diferente do que foi originalmente - não simplesmente porque o significado da palavra mudou mas sim porque também o fez o mapa social em sua totalidade. As relações sociais, a natureza do poder político e sua relação com o poder econômico, e a forma da propriedade mudaram. Agora é possível ter um novo tipo de democracia que está confinada a uma esfera puramente política e judicial - aquilo que alguns denominam democracia formal - sem destruir os alicerces do poder de classe. O poder social passou às mãos do capital, não só em razão de sua influência direta na política, mas também por sua incidência na fábrica, na distribuição do trabalho e dos recursos, assim como também via os ditames do mercado. Isto significa que a maioria das atividades da vida humana fica fora da esfera do poder democrático e da prestação de contas.

O alerta que a autora nos faz está claro e vale a pena reforçar: em que medida as bandeiras de participação democrática, política, alardeada pela sociedade capitalista não é apenas formal e não substantiva? Como fazer com que propostas como aquela expressa pelo modelo de gestão democrática e participativa não seja apenas mais um jogo de cena do capital para manter o status quo?

Para finalizar e apontar possibilidades, diremos que romper com essa lógica do capital não quer dizer que "jogamos fora a criança com a água do banho". É preciso, dentro de uma lógica dialética e revolucionária, aproveitar as melhores produções da escola burguesa, ou seja, no que diz respeito ao tema que nos interessa, os espaços coletivos de organização política da comunidade escolar, como os Conselhos Escolares e Colegiados Estudantis, mas usando-os como espaço para uma prática social revolucionária. Uma parte de um texto de Pistrak (2009, p.23) é elucidativo disso que defendemos. Vejamos:

Alguns conceitos, terminologia, formas externas dos detalhes podem 
continuamente transferir-se para a nova escola, mas o conteúdo, as formas organizacionais e os objetivos devem ser novos. As idéias e métodos copiados da pedagogia burguesa pela nova escola (digamos: trabalho, autodireção) devem receber novo colorido, nova interpretação. Estas idéias e métodos devem partir de novos objetivos de formação, e estes, em essência, partem inteiramente das tarefas e objetivos da construção revolucionária. Estes objetivos, basicamente, resumem-se na formação da pessoa, a qual reconheceria a si mesmo como membro do coletivo internacional das pessoas que lutam contra o regime caduco por uma vida nova, por uma nova ordem social, na qual não haverá divisão em classes sociais. Concretamente, a questão conduz a que as novas gerações compreendam, em primeiro lugar, em que consiste a essência deste processo de luta que abarca a humanidade; em segundo, que lugar a classe oprimida ocupa nesta luta; e, em terceiro, que lugar cada jovem deve ocupar nesta luta.

Muitas são as questões quando o tema são as escolas públicas. Tanto em áreas urbanas quanto no campo estão em precárias condições de infraestrutura. No campo a situação se agrava ainda mais frente uma vez que a sociedade capitalista prioriza a cidade, estabelecendo padrões urbanos em detrimento do campo. Por isso a importância de estarmos atentos ao processo contraditório - a gestão democrática, é um exemplo determinado pelos interesses dominantes presentes nas relações sociais de produção e de convivência. Por isso é importante, retomando Pistrak, que ideias e métodos devem partir de novos objetivos de formação, e estes, em essência, partem inteiramente das tarefas e objetivos da construção revolucionária. A educação pública é algo a ser construído no âmbito das relações contraditórias que impulsionam as sociedades!

\section{REFERÊNCIAS}

Brasil. (1997). Lei de Diretrizes e Bases da Educação Nacional, no 9.394 de dezembro de 1996. Brasília: Senado Federal.

BRASIL. (1997). Parâmetros Curriculares Nacionais: Introdução aos Parâmetros Curriculares Nacionais. Brasília: MEC/ Secretaria de Educação Fundamental.

BRASIL, TV ESCOLA. (2001). Programa Salto para o Futuro/Série Escolas Rurais e Classes Multisseriadas. Disponível em www.tvebrasil.com.br/saltoparaofuturo/boletim2001.

BRASIL, INEP. Sinopses Estatísticas da Educação Básica de 1997 a 2007. Disponíveis em Disponíveis em www.inep.gov.br, link portal INEP/Informações Estatísticas/Sinopses Estatísticas.

BRASIL, MEC/SECAD. Elementos para um Plano Nacional de Educação do Campo. Disponível em www.mec.gov.br/secad/ educação no campo.

BRASIL/MEC/SECAD. Por uma Política de Educação do Campo. Disponível em WWW.mec.gov.br/secad 
BRASIL, TV ESCOLA. (2005). Programa Salto para o Futuro/Série Gestão Democrática da $\quad$ Educação. $\quad$ Disponível em www.tvebrasil.com.br/saltoparaofuturo/boletim2005.

BRASIL, MEC/SECAD (2010). Projeto Base (Programa Escola Ativa). Disponível em http://portal.mec.gov.br/secad (link Programas e Ações - Escola Ativa - Projeto Base).

BRASIL, MEC/SECAD (2010). Orientações Pedagógicas (Programa Escola Ativa). Disponível em http://portal.mec.gov.br/secad (link Programas e Ações - Escola Ativa Orientações Pedagógicas).

CARDOSO, M. A.; LARA, A. M. B. (2009) Sobre as Funções Sociais da Escola. In: Anais do IX Congresso Nacional de Educação - EDUCERE: Políticas e Práticas Educativas: desafios da aprendizagem. Curitiba, PR: Champagnat/PUC. CD ROM. Disponível em http://www.pucpr.br/eventos/educere/educere2009/anais/pdf/1929_1160.pdf

CURY, C. R. J. (2001). O Conselho Nacional de Educação e a Gestão democrática. In OLIVEIRA (org.). Gestão Democrática da Educação: desafios contemporâneos. 3 ed. Petrópolis, RJ: Vozes. p. 199-206.

DEMO, P. (2006). Pobreza política: a pobreza mais intensa da pobreza brasileira. Campinas, SP: Autores Associados.

FONSECA, M. (2001) O Banco Mundial e a Gestão da Educação Brasileira. In OLIVEIRA (org.). Gestão Democrática da Educação: desafios contemporâneos. 3 ed. Petrópolis, RJ: Vozes. p. 43-63.

FRIGOTTO, G. (2007). A Relação da Educação Profissional e Tecnológica com a Universalização da Educação Básica. Revista Educação e Sociedade. Campinas, vol. 28, n. 100, p. 1129-1152, Especial - Out. 2007. Disponível em <http://www.cedes.unicamp.br

HAGE, S. Mufarrej. (2006). A Realidade das Escolas Multisseridas frente às conquistas na Legislação Educacional. In: Anais da 29a Reunião Anual da ANPED: Educação, Cultura e Conhecimento na Contemporaneidade: desafios e compromissos manifestos. Caxambu: ANPED. CD ROM.

HAGE, S. Mufarrej. (2007). Movimentos Sociais do Campo e a Afirmação do Direito à Educação: pautando o debate sobre as escolas multisseriadas na Amazônia Paraense. Revista Brasileira de Estudos Pedagógicos. Jan. 2007.

LUCE, M. B.; MEDEIROS, I. L. P. (2008). Gestão democrática Escolar. Disponível em http://www.portaleducacao.com.br/pedagogia/artigos/2666/gestao-democratica-escolar

MENEZES, E. T; SANTOS, T. H. (2002). "Classes multisseriadas" (verbete). Dicionário Interativo da Educação Brasileira - EducaBrasil. São Paulo: Midiamix Editora. Disponível em www.educabrasil.com.br/dicionario. Acesso em 9/1/2007

MÉSZÁROS, I. (2005). A Educação para além do Capital. São Paulo: Boitempo. 
MÜLLER, M. T. (2006). A Educação em Campinas - Suporte Político no Início da Primeira República. In: ANAIS do VII Seminário Nacional de Estudos e Pesquisas. 20 anos de HISTEDBR: navegando pela História da Educação Brasileira. Campinas, SP: UNICAMP/HISTEDBR. CD ROM.

OLIVEIRA, D. A. (2001). Educação e Planejamento: a escola como núcleo da gestão. In OLIVEIRA (org.). Gestão Democrática da Educação: desafios contemporâneos. 3 ed. Petrópolis, RJ: Vozes. p. 64-100.

PARO, V. H. (1987). A Utopia da Gestão Escolar Democrática. Revista Cadernos de Pesquisa, n. 60, fev. 1987. São Paulo: Fundação Carlos Chagas. Disponível em http://www.fcc.org.br/pesquisa/publicacoes/cp/arquivos/921.pdf

PISTRAK, M. M. (Org.). (2009) Trad. Luiz Carlos de Freitas e Alexandra Marenich. A comuna escolar. São Paulo: Expressão Popular.

PIZA, F. F; SENA, L. B. (2001). PMG 3 - Escola Ativa. Salto para o Futuro. Disponível em www.tvebrasil.com.br/saltoparaofuturo/boletim 2001.

QUEIROZ, M. M. A.; MENDES SOBRINHO, J. A. (2004) A Escola Ativa: aspectos do ensino de Ciências Naturais em Classes Multisseriadas da zona rural de Teresina. In: Anais do III Encontro de Pesquisa em Educação da UFPI. Disponível em http://www.ufpi.br/mesteduc/eventos/iiiencontro/gt14/escola_ativa.pdf

RIBEIRO, Marlene. (2011). Educação do Campo e Escola Ativa: contradições na política educacional no Brasil Rural. Educação em Revista. Marília, v. 12, n. 2, p. 23-40. Jul./dez. 2011. Disponível

em http://www2.marilia.unesp.br/revistas/index.php/educacaoemrevista/article/viewFile/2485/ $2022 \mathrm{v}$

ROSA, Julia Mazinini; BEZERRA, Maria Cristina dos Santos. (2013). A Busca pelo consenso Neoliberal no Campo: aspectos históricos do Programa Escola Ativa. Revista HISTEDBR On-line, Campinas, $n^{\circ} 50$ (especial), p. 31-47, mai 2013. Disponível em http://www.fe.unicamp.br/revistas/ged/histedbr/article/viewFile/5473/4376

ROSA, Julia Mazinini; BEZERRA, Maria Cristina dos Santos. (2014). A Qualidade Educacional para o Programa Escola Ativa. Revista Exitus. v. 4. n. 1. Jan./jun. 2014. Disponível em http://www.ufopa.edu.br/revistaexitus/revistas/vol.-4-no.-1-2013-2014-issnimpresso-2236-2983-issn-eletronico-2237-9460/artigos/a-qualidade-educacional-para-oprograma-escola-ativa/view

ROSAR, M. F. F. (2001). A Municipalização como Estratégia de Descentralização e de Desconstrução do Sistema educacional Brasileiro. In OLIVEIRA (org.). Gestão Democrática da Educação: desafios contemporâneos. 3 ed. Petrópolis, RJ: Vozes. p.105-140.

SANFELICE, J. L. (2005). Da Escola Estatal Burguesa à Escola Democrática e Popular: considerações historiográficas. In: LOMBARDI, J. C; SAVIANI, D; NASCIMENTO, M. I. M. (orgs.) A Escola Pública no Brasil: história e historiografia. Campinas, SP: Autores Associados. (p. 89-105) 
SANTOS, Stella R; PINHO, A. S. T. (2002). A Historia in(visível) do Currículo no Cotidiano de Professoras da Roça, em Classes Multisseriadas In: Anais da 25a Reunião Anual da ANPED: Educação: manifestos, lutas e utopias. Caxambu: ANPED. CD ROM.

SAVIANI, D. (1980) Educação: do Senso Comum à Consciência Filosófica. SP: Cortez Editora; Autores Associados.

(2005). Pedagogia Histórico-Crítica: primeiras aproximações. 9 ed. Campinas, SP; Autores Associados.

SOUZA, R. F. (2006). Lições da Escola Primária. In: O Legado Educacional do Século XX no Brasil. SAVIANI, D. [et al.]. 2 ed. Campinas, SP: Autores Associados. p. 109-161.

WOOD, Elen. Disponível em http://bibliotecavirtual.clacso.org.ar/ar/libros/campus/marxispt/cap. 18.doc

Notas

1 Pesquisadora e Coordenadora do Programa de Pós-Graduação da Faculdade de Educação/UNICAMP. Mestre e Doutora em Educação pela UNICAMP. Coordenadora do Programa de Pósgraduação em Educação da Faculdade de Educação da Unicamp. E-mail: mararmj@unicamp.br

Professora Doutora do Centro de Ciências Humanas e Sociais/UFMS, especialista em Educação/Formação Docente pela UNIDERP, Mestre em Educação pela UFMS, doutora em Filosofia e História da Educação pela UNICAMP. E-mail: maria.cardoso@ufms.br

3 Após a Lei 11.274, de 6 de fevereiro de 2006, que alterou o Ensino Fundamental de oito $\left(1^{\mathrm{a}}\right.$ a $8^{\mathrm{a}}$ série) para nove anos ( $1^{\circ}$ ao $9^{\circ}$ ano), estas escolas passaram a ser chamadas, também, de multianuais.

4 Disponível em www.educabrasil.com.br/dicionario interativo da educação brasileira. Letra c, página 2/classes multisseriadas.

$5 \quad$ Fernando Ferreira Piza e Lílian Barboza de Sena eram, respectivamente, coordenador e assessora técnica da Proposta Pedagógica Escola Ativa quando de sua implantação.

6 Dados colhidos nas Sinopses Estatísticas da Educação Básica de 2000 e 2013. Disponíveis em www.inep.gov.br, link portal INEP/Informações Estatísticas/Sinopses Estatísticas.

Disponível em http://bibliotecavirtual.clacso.org.ar/ar/libros/campus/marxispt/cap. 18.doc, p. 3.

Recebido: julho/14 Aprovado: agosto/14 